\title{
INCREASING THE SPECIFIC RATE OF CONTINUOUS PHASE MODULATION SIGNALS
}

\author{
Victor Banket $^{1}$, Sergei Manakov ${ }^{2}$ \\ ${ }^{1}$ O.S. Popov ONAT, A.G. Zyuko Telecommunication Theory Department, ${ }^{2}$ O.S. Popov ONAT, Information Technologies Department
}

Abstract. A method has been developed for increasing the specific rate of frequency modulation signals with a continuous phase based on the use of the properties of composite Walsh-Barker sequences. The proposed method is applicable for multi-position signals. Simultaneously, the tasks of synchronization and registration of processing results are solved. The increase in the efficiency of digital signal transmission systems is theoretically justified.

Keywords: continuous phase modulation, specific rate, Walsh-Barker composite sequences, performance indicators of a transmission system

\section{ZWIĘKSZENIE PRĘDKOŚCI WLAŚCIWEJ SYGNALÓW O MODULACJI CZĘSTOTLIWOŚCIOWEJ Z CIĄGLĄ FAZĄ}

Streszczenie. Opracowano i zbadano eksperymentalnie metodę zwiększania prędkości właściwej sygnałów modulacji częstotliwościowej z ciągła faza oparta na wykorzystaniu właściwości sekwencji złożonych Walsha-Barkera. Zaproponowana metoda może być zastosowana do sygnałów wielopozycyjnych. Jednocześnie rozwiazywane sa zadania synchronizacji i rejestracji wyników przetwarzania. Wzrost wskaźników wydajności systemów cyfrowego przesyłania sygnałów jest teoretycznie uzasadniony.

Słowa kluczowe: modulacja częstotliwościowa z ciągłą fazą, prędkość właściwą, sekwencje złożone Walsha-Barkera, wskaźniki wydajności systemu przesyłowego

\section{Introduction}

The modern world lives in an era of rapid development of broadband wireless technologies. Transmission rate and noise immunity of digital information are the indicators largely determined by the signal modulation/demodulation methods used in the channel.

Discrete signals of continuous phase modulation (CPM) are characterized by a constant envelope, the absence of phase jumps during modulation, high rates of energy and frequency efficiency, as well as resistance to phase distortions introduced by a fading channel [1].

The traditional method of increasing the specific rate is the use of multi-position signals. In LTE, OFDM modulation is a widely used method. Each OFDM signal subcarrier is modulated by 4-, 16-, and 64-position quadrature amplitudephase modulation (QPSK, 16-QAM, or 64-QAM). Accordingly, one symbol on one subcarrier carries 2,4 , or 6 bits. In addition, for phase separation it is necessary to use coherent quadrature reference oscillations, information about which in the implemented LTE systems is transmitted as part of special sync packages.

Our preliminary studies [2] have shown that the ideas of the method for constructing composite signals can be effectively used to increase the specific transmission rate of digital information.

The task of this work is the development and experimental study of a method for increasing the specific transmission rate of digital information through channels with the CPM signals. Experimental results were obtained by modelling in the Hewlett Packard VEE object-oriented graphical programming environment.

\section{Multi-position CPM}

Discrete CPM signal has the form [1]

$$
s(t)=S_{0} \cos \left[\omega_{s} t+\varphi(t)\right],
$$

where the current phase in the $n$-th interval $[n T<t<(n+1) T]$ is

$$
\varphi_{(n)}(t)=2 \pi h \sum_{k \leq n} u_{k} g_{\varphi}(t-k T) .
$$

Here $S_{0}$ is the amplitude, $\omega_{s}$ is the signal frequency, $T$ is the duration of the elementary symbol, $h$ is the modulation index, and $u_{k}$ are modulating symbols. From the expression (1) it follows that the CPM signal is a phase modulation signal of a harmonic carrier with a phase varying in time according to the law (2) with the amplitude $\Phi_{k}=2 \pi h u_{k}$ of the phase pulse:

$$
\varphi_{(n)}(t)=\sum_{k \leq n} \Phi_{k} g_{\varphi}(t-k T),
$$

where $g_{\varphi}(t)$ is the shape of the phase smoothing pulse. As with phase modulation, the limits of variation of the amplitude of the phase pulse $\Phi_{k}$ are determined by the interval $(0 \ldots 2 \pi)$. In this case, the required number of positions $M$ of the multiposition CPM signal can be obtained by splitting this interval with a step (phase index of the CPM signal)

$$
\delta \Phi=\frac{2 \pi}{M-1} .
$$

If the information symbols $u_{i}$ are selected from the alphabet of volume $M: \quad u_{i} \subset\{0,1,2,3 \ldots(M-1)\}$, then the values of the phase amplitudes (3) of the CPM signal (1) will be

$$
\Phi_{i}=f\left(v_{i}\right) \delta \Phi u_{i} .
$$

Expression (5) together with (3) is the rule of the multi-position CPM modulation.

As usual, with multi-position modulation, the specific rate increases to

$$
R_{M}=\log _{2} M \text { bits/symbol. }
$$

That is, in this case, each character of the signal carries $\log _{2} M$ bits of information.

Consider, following the ideas of [2], a different (alternative) method of increasing the specific rate. This will be performed with simple example of the transmission of two different characters of multi-position messages. In the following, this example will be generalized to a large number of independent messages.

\section{Forming a composite signal with high specific rate}

As shown in [3], the composite signal is composed of elementary symbols (or sequences of symbols) according to the rules of the generating sequence, which coincides with the Barker code. We use Walsh orthogonal sequences as elementary sequences. 
A set of binary Walsh sequences of length $m=8$ has the form [3]:

$$
W_{8}=\left[\begin{array}{l}
w_{0} \\
w_{1} \\
w_{2} \\
w_{3} \\
w_{4} \\
w_{5} \\
w_{6} \\
w_{7}
\end{array}\right]=\left[\begin{array}{llllllll}
+ & + & + & + & + & + & + & + \\
+ & - & + & - & + & - & + & - \\
+ & + & - & - & + & + & - & - \\
+ & + & + & + & - & - & - & - \\
+ & - & - & + & + & - & + \\
- & - & - & - & + & + & + & + \\
+ & - & + & - & - & + & - & + \\
+ & - & - & + & - & + & + & -
\end{array}\right] .
$$

The sequences in the ensemble (7) are mutually orthogonal, their total number is

$$
M_{\mathrm{W}}=m .
$$

To send two independent messages $U_{0}$ and $U_{1}$, we choose two sequences from the set (7), written below as row-matrices

$$
\begin{aligned}
& w_{0}=[++++++++], \\
& w_{1}=[+-+-+-+-] .
\end{aligned}
$$

We use the string-matrix of the Barker code of length $M_{\mathrm{B}}=7$ as the generating sequence.

$$
C 7=[+-++---] .
$$

Or, in a formal record

$$
C 7=\left[\begin{array}{lllllll}
c_{1} & c_{2} & c_{3} & c_{4} & c_{5} & c_{6} & c_{7}
\end{array}\right] .
$$

The matrix form of writing sequences allows a compact representation of the formation method. The composite sequence is determined by the product of matrices of selected Walsh elementary sequences (9) or (10) by the matrix of the generating Barker sequence (12):

$$
\left[C 7 / w_{i}\right]=\left[w_{i}\right][C 7] .
$$

where $i=(0 . .1)$ is the number of the selected elementary sequence. Since the Barker sequence (12) contains a set of constant numbers, the sequence (13) can be represented as

$$
\left[C 7 / w_{i}\right]=\left[\begin{array}{llllllll}
w_{i} c_{1} & w_{i} c_{2} & w_{i} c_{3} & w_{i} c_{4} & w_{i} c_{5} & w_{i} c_{6} & w_{i} c_{7}
\end{array}\right] .
$$

Record (14) defines simple ways of software or hardware implementation of the formation method: the selected elementary sequence is fed to the input of a chain of serially connected shift registers, the outputs of which are added after multiplying by weighting factors of the generating sequence (14). The timing diagram of the $C 7 / w_{0}$ composite sequence formed in this way is shown in Fig. 1.

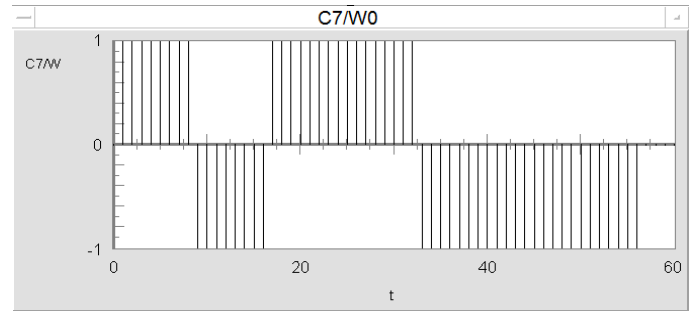

Fig. 1. Timing diagram of the composite sequence $C 7 / w_{0}$

In accordance with the record (14), we form composite sequences modulated in amplitude by the information symbols $U_{0}$ and $U_{1}$

$$
\begin{aligned}
& {\left[U_{0} C 7 / w_{0}\right]=} \\
& =\left[\begin{array}{llllllll}
U_{0} w_{0} c_{1} & U_{0} w_{0} c_{2} & U_{0} w_{0} c_{3} & U_{0} w_{0} c_{4} & U_{0} w_{0} c_{5} & U_{0} w_{0} c_{6} & U_{0} w_{0} c_{7}
\end{array}\right] \\
& {\left[U_{1} C 7 / w_{1}\right]=} \\
& =\left[\begin{array}{llllllll}
U_{1} w_{1} c_{1} & U_{1} w_{1} c_{2} & U_{1} w_{1} c_{3} & U_{1} w_{1} c_{4} & U_{1} w_{1} c_{5} & U_{1} w_{1} c_{6} & U_{1} w_{1} c_{7}
\end{array}\right]
\end{aligned}
$$

We assume that the sum of the composite modulating signals is transmitted over the channel with the chosen modulation method (for example CPM).

$$
S_{\text {chan }}=\left[U_{0} C 7 / w_{0}\right]+\left[U_{1} C 7 / w_{1}\right] .
$$

From the form of the modulating signal (16) the following statements follow:

1) In this case, each modulating signal $S_{\text {chan }}$ contains information about two independent information symbols $U_{0}$ and $U_{1}$. When using the sum of composite signals (17) for transmission over the channel, it is possible to double the specific rate, since each modulating signal carries information about two independent information symbols,

2) Removing the transmitted information symbols from the evaluation $\hat{S}_{\text {chan }}$ of the transmitted channel signal involves solving the following tasks:

a) The task of separating composite signals contained in the sum (17),

b) The task of optimal processing of each of the separated composite signals in order to extract the estimates of the transmitted information symbols $U_{0}$ and $U_{1}$.

To solve these problems, we use matched filtering of the transmitted sum (17).

\section{Separation and optimal processing of composite signals}

Separation of composite signals contained in the sum (17) is performed using matched filters (MF). A feature that can be used for separation is the presence of different orthogonal elementary Walsh sequences $\left(w_{0}\right.$ and $\left.w_{1}\right)$ in the composition of the divided signals (15) and (16). The orthogonality properties of these sequences are realized by applying matched filters. In accordance with the signal processing theory, the impulse response of a filter matched with a discrete signal $s(t)$ coincides with an accuracy of a constant factor $(a)$ with a mirror image of the signal waveform:

$$
h(t)=a s\left(t_{0}-t\right),
$$

where $t_{0}$ is the MF output sample moment. In processing sequences, the concept of a filter matched with $a$ sequence is also applicable. The impulse response of the filters matched with the elementary sequences (9) and (10) mentioned above are

$$
\begin{aligned}
& {\left[h\left(w_{0}\right)\right]=\left[\begin{array}{llllllll}
1 & 1 & 1 & 1 & 1 & 1 & 1 & 1
\end{array}\right],} \\
& {\left[h\left(w_{1}\right)\right]=\left[\begin{array}{llllllll}
-1 & 1 & -1 & 1 & -1 & 1 & -1 & 1
\end{array}\right]}
\end{aligned}
$$

The orthogonality properties of the said elementary sequences are manifested in the values of the correlation functions at the reference time $t_{0}$, and the values of the autocorrelation (ACF) (20) and the cross-correlation (CCF) (21) functions at the reference time $t_{0}$ are equal to:

$$
\begin{gathered}
{\left[R\left(w_{0}, w_{0}\right)\right]=\left[w_{0}\right]\left[h\left(w_{0}\right)\right]=R_{\max }=m=8,} \\
{\left[R\left(w_{1}, w_{1}\right)\right]=\left[w_{1}\right]\left[h\left(w_{1}\right)\right]=R_{\max }=m=8 .} \\
{\left[R\left(w_{1}, w_{0}\right)\right]=\left[w_{1}\right]\left[h\left(w_{0}\right)\right]=0 .}
\end{gathered}
$$

In accordance with (21), the CCF values of the selected sequences at the reference time $t_{0}$ are equal to 0 , and the ACF values (20) acquire the maximum values $R_{\max }=m=8$, equal to the length of the sequences $m=8$.

To extract the transmitted information symbols, we use the matched filtering of the transferred sum (17). From the form of the composite signal (15), which is included in the sum (17), it follows that to select the information symbol $U_{0}$, it is sufficient to use a filter matched with the elementary sequence $w_{0}$. Processing the first term of the sum (17) with a matched filter with the impulse response $h\left(w_{0}\right)$, taking into account the result of the ACF calculation, gives

$$
S_{0}=\left[U_{0} C 7 / w_{0}\right]\left[h\left(w_{0}\right)\right]=U_{0} m[C 7] .
$$

At the same time, the result of processing the second summand of (17) with the filter with impulse characteristic $h\left(w_{1}\right)$, taking into account the result of calculating the CCF (21), gives (by the orthogonality property) zero result

$$
\left[U_{1} C 7 / w_{0}\right]\left[h\left(w_{1}\right)\right]=0 \text {. }
$$


At the same time, like (22) it is possible to extract the message symbol $U_{1}$ :

$$
S_{1}=\left[U_{1} C 7 / w_{1}\right]\left[h\left(w_{1}\right)\right]=U_{1} m[C 7] .
$$

From the form of results (22), (24) that are consistent with the elementary sequences $w_{0}$ and $w_{1}$ used, it is possible to obtain estimates of the transmitted information symbols $U_{0}, U_{1}$. To solve this problem, the subsequent processing of the results (22) and (24) with a filter matched with the $C 7$ generating sequence, whose impulse response is determined by the expression matched with (10), is necessary: $h(C 7)=[---++-+]$. As a result of processing, the SF outputs increase by the value of the length of the generating sequence $M_{\mathrm{B}}$ and will be as follows

$$
\begin{gathered}
S_{0}=\left[U_{0} C 7 / w_{0}\right]\left[h\left(w_{0}\right)\right]=U_{0} m[C 7][h(C 7)]=m M_{B} U_{0}, \\
S_{1}=\left[U_{1} C 7 / w_{1}\right]\left[h\left(w_{1}\right)\right]=U_{1} m[C 7][h(C 7)]=m M_{B} U_{1} .
\end{gathered}
$$

In this case, similarly to (23) the results of mismatched filtering appear:

$$
\left[U_{0} C 7 / w_{0}\right]\left[h\left(w_{1}\right)\right]=0,\left[U_{1} C 7 / w_{1}\right]\left[h\left(w_{0}\right)\right]=0 .
$$

Expressions (25..27) are key, explaining the possibility of separating composite signals. They can be generalized to the number of simultaneously transmitted and separated composite signals of more than two. We choose from the ensemble of Walsh sequences (7) some subset of $\left\{w_{i}\right\}$, where $i$ is the number of current sequence, $i \leq m$. Similarly to (15) we form composite signals for transmitting the $i$-th information symbols:

$$
\begin{aligned}
& {\left[U_{i} C 7 / w_{i}\right]=} \\
& =\left[\begin{array}{llllllll}
U_{i} w_{i} c_{1} & U_{i} w_{i} c_{2} & U_{i} w_{i} c_{3} & U_{i} w_{i} c_{4} & U_{i} w_{i} c_{5} & U_{i} w_{i} c_{6} & U_{i} w_{i} c_{7}
\end{array}\right] .
\end{aligned}
$$

Similarly to (16) we form the aggregate modulating composite signal:

$$
S_{\text {chan }}=\sum_{i=1}^{M_{W}}\left[U_{i} C 7 / w_{i}\right] .
$$

Thus, the cumulative modulating composite signal contains information on $M_{W}$ independent transmitted information symbols. This increases the specific rate. When using the $M$-positional modulation method (for example, $M$-CPM), the specific rate increases to

$$
R_{(C W B), M}=M_{W} \log _{2} M(\mathrm{bit} / \mathrm{symbol}) .
$$

The separation of composite signals and the extraction of information symbols is made similarly to the above (25..27) using a set of filters matched with the "working" subset $\left\{w_{i}\right\}$.

\section{Self-synchronization property of composite signals}

In addition to the above advantages of composite signals, their important property of self-synchronization should be noted. As noted in [3], the author R.H. Barker proposed a kind of sequence of characters (called in digital technology as the Barker code), which has a unique property (the so-called self-synchronization property) and is currently used to build time synchronization systems. In [2], it was shown that this property can be enhanced by applying the composition method based on the use of Barker sequences instead of binary symbols in the Barker code. In the case of the use of composite Walsh-Barker sequences should also be expected to enhance the selfsynchronization property. Consider this question in more detail. The result of processing the Barker $C 7$ sequence with a matched filter is shown in Fig. 2. In accordance with the theory [4], the result of processing coincides with the aperiodic autocorrelation function (ACF) of such a sequence. When calculating the ACF, it is necessary to take into account that due to the processing of Walsh sequences in separating matched filters, the "weight" of each «1» in the received Barker sequence increases by an amount equal to the length $m$ of the Walsh sequence.
With this, ACF has the form

$$
R(k)=\frac{m}{M} \sum_{i=0}^{M_{B}} c(i) c(i+k),
$$

where $R(k)=m M_{\mathrm{B}}$ when $k=0$.

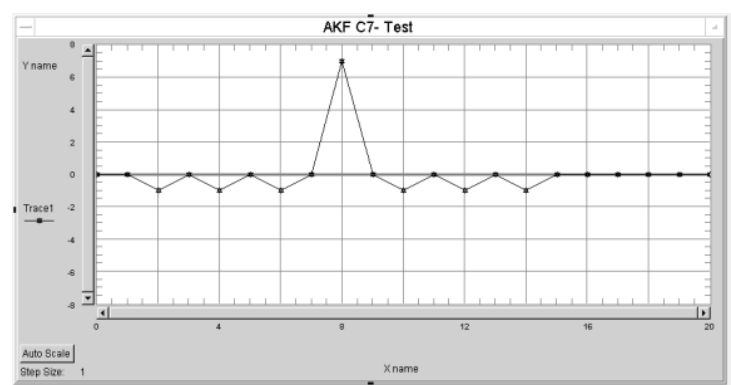

Fig. 2. The result of processing the Barker sequence $C 7$ by the matched filter

The spike value of the autocorrelation function in accordance with (31) reaches the value of $R(0)=m M_{\mathrm{B}}$. At the same time, as follows from expressions (25), (26), the emission values are $S_{0}=m M_{\mathrm{B}} U_{0}, S_{1}=m M_{\mathrm{B}} U_{1}$ and contain information about the transmitted information symbols $U_{0}$ and $U_{1}$. It is clear that in order to estimate the true values of the transmitted symbols, it is necessary to perform normalization by dividing the processing results by a constant factor $\left(m M_{\mathrm{B}}\right)$. This unique form of the ACF composite Walsh-Barker sequence can be used not only for synchronization, but also for recording the results of separation and processing of composite signals. This unique form of the ACF composite Walsh-Barker sequence can be used not only for synchronization, but also for registration the results of separation and processing of composite signals. Indeed, as follows from expressions (25) and (26), the ACF spikes appear at the outputs of the corresponding matched filters, the values of which contain the processing results $\left\{S_{0}=m M_{\mathrm{B}} U_{0}\right.$ $\left.S_{1}=m M_{\mathrm{B}} U_{1}\right\}$. In other words, the tasks of synchronization in time and registration of processing results are simultaneously solved. This method of transmitting information differs in that the position of the ACF spike on the time axis can be used to estimate the reference point of the spike amplitude value. (i.e., for time synchronization, moreover, the amplitude of the ACF spike contains information about the transmitted symbol). The outlined feature of composite signals and the results of their processing by matched filters was verified by simulation in HP VEE. The simulation results are illustrated with time diagrams (Fig. 3 and Fig. 4).

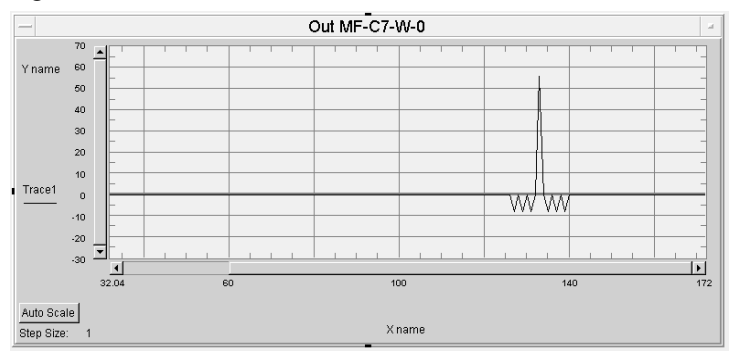

Fig. 3. The timing diagram of the process at the MF output when processing of the composite signal C7/wo. Digital interference is absent. The ACF spike value $R(0)=56$ marks the reference point

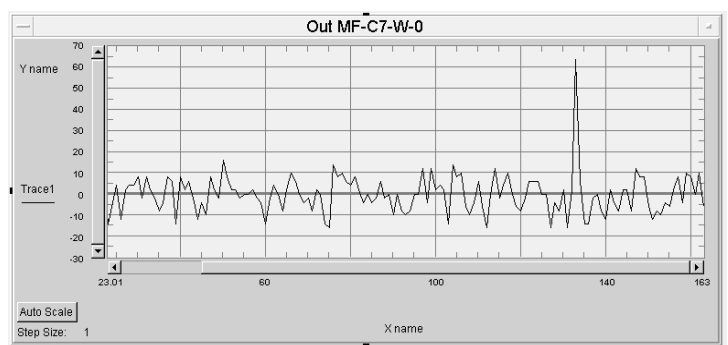

Fig. 4. The timing diagram of the process at the MF output when processing the composite signal C7/wo under the action of digital interference. The diagram demonstrates the self-synchronization property of the composite signal: the ACF spike is clearly outlined against the background of the digital noise. Moreover, in the subsequent emissions of false synchronization of the same magnitude are absent 
In the simulation, the composite signals (15) and (16) in the form of sum (17) were transmitted over a channel with the CMP. At the same time, a sequence of binary independent equiprobable symbols, which imitated digital interference, was transmitted over the same channel. Registration of processes within the test cycle of a given length $N_{c}$ was envisaged. In the middle of this cycle, the above-mentioned composite signals were transmitted. The separation of signals is implemented using matched filters as described above.

On the question of the optimal processing of composite signals, the following should be noted. If the energy of each symbol of the composite sequence is Es, then, in accordance with formula (30), when forming the ACF spike of composite signal with the length of the elementary sequence $m$ and the length of the generating sequence $M_{\mathrm{B}}$, the amplitude of the spike increases to

$$
R(k)_{\max }=M_{B} m E_{s} \text {, when } k=0 .
$$

This is due to the symbols energy accumulation effect of the composite sequence in the matched filters during the formation of the ACF. It provides an increase in the noise immunity of the ACF spikes registration. As in the construction of any time synchronization systems, in this case, one should evaluate the reliability of the synchronization signal extraction (and the reliability of the above-described method of the processing results recording) when there is possible interference in the channel. For registration of clock signals, we use a threshold detector. For registration of synchronization signal, we use a threshold detector.

The threshold sync detector consists of a filter matched with a clock signal. The filter output is fed to the detector with a fixed threshold $L$. When applying a composite signal to the MF input the response at its output is determined by the ACF form (Fig. 3, Fig. 4). Exceeding the threshold $\mathrm{L}$ is registrated as a mark used for time synchronization. The quality of such systems is determined by the following indicators:

1) False detection probability, $P_{\mathrm{fd}}$. False detection of the sync signal occurs whenever a segment of digital interference at the input of the SF takes the form of a sync signal.

2) Probability of skipping the sync signal, $P_{\text {skip }}$, on account of suppressing the sync signal with random noise coming from the channel. A sync skipping occurs whenever random noise coming from a channel takes the form inverse to the shape of the sync signal and, accordingly, reduces the response level at the output of the matched filter.

These parameters $\left(P_{\mathrm{fd}}\right.$ and $\left.P_{\text {skip }}\right)$ depend on the magnitude of the threshold level $L$ of the sync signal detector, the properties of the Walsh-Barker signal, digital interference, and random noise. As can be seen from the curves in Fig. 3 and Fig. 4, the threshold level $L$ of the sync signal can be set from the minimum $R_{\min }=0$ to the maximum $R_{\max }=R(0)=m M_{\mathrm{B}}=56$.

Moreover, the probabilities of each of the erroneous events depend on the threshold value in such a way that the optimum can be between these extreme values. In order to determine the value of the optimal threshold, a simulation of the sync signals false detection registration of a composite signal was performed using HP VEE software. Fig. 5 illustrates the simulation results.

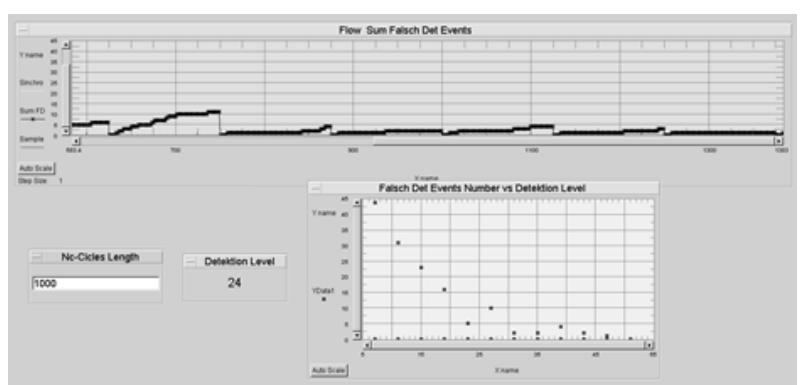

Fig. 5. The working panel of the program of experimental determination the amount of the sync signal false detections: on the upper graph - the symbols accumulation process corresponding to each false detection; on the lower graph - dots mark the values of the amounts of false detections depending on the value of the automatically set threshold level $L$
From the simulation results it follows:

1) The ammount of false sync detections has the highest value when setting the threshold level $L$ close to zero,

2) As the $L$ value increases, the number of false detections decreases significantly. In particular, for $L=24$, the number of false detections is 5 for the length of the measurement cycle $N_{\mathrm{c}}=1000$ and the probability of sync signal false detection $R_{\mathrm{fd}}=5 \cdot 10^{-3}$

3) From the data in Fig. 5 it is clear that with a subsequent increase in the threshold level, the number of false detections sharply decreases.

\section{Conclusion}

The ways to increase the specific rate of the modulated signal are considered:

1) The use of $M$-position modulation, in which the entire dynamic range of the modulating signal is divided into $M$ levels. The transition from binary information symbols to $M$-level symbols is carried out using the Gray code. The canonical example of using $M$-positional modulation is QAM.

2) A new method for increasing the specific rate is described above in this article (based on the use of composite sequences).

3) The method described is applicable to multi-position signals.

4) The increase in the specific rate of the modulated signal leads to an increase in the performance indicators of digital signal transmission systems, which include the specific speed: energy efficiency $\beta=\frac{R}{P_{s} / N_{0}}$ and frequency efficiency $\gamma=\frac{R}{F}$.

5) In the case when the transmission system developer pursues the goal of increasing the frequency efficiency, it is necessary to find a compromise between the equipment complexity with the use of the above method and the gain from saving bandwidth.

\section{References}

[1] Banket V. L.: Signal'no-kodovye konstruktsii v telekommunikatsionnykh sistemakh. Feniks, Odessa 2009.

[2] Banket V., Manakov S.: Composite Walsh-Barker sequences. 9th International Conference on Ultrawideband and Ultrashort Impulse Signals. Conference Proceedings, Odessa 2018, 343-347.

[3] Barker R. H.: Ground synchronizing of binary digital system. Communication theory 7(2)/1953, 273-287.

[4] Banket V. L.,Tokar M. I.: Kompozitnyye kody Barkera. Tsifrovyye tekhnologii 2/2007, 7-18.

\section{Prof. Victor Banket}

e-mail: vlbanket@ukr.net

Professor of the Electrical communications theory department, O.S. Popov Odessa National Academy of Telecommunications. Born in 1938, Sevastopol city. Interests: development of the theory of noise immunity and efficiency of information transmission systems. More than 20 copyright certificates for inventions, 12 of which are embedded in the equipment of satellite communication systems. Author of 4 monographs and 6 textbooks. Member of IEEE. He has several government awards.

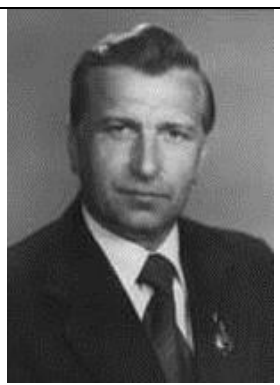

ORCID ID: 0000-0001-8469-641X

\section{Sergei Manakov}

e-mail:manakov@onat.edu.ua

In 2004 graduated from the A.S. Popov Odessa National Academy of Telecommunications. Interests: information technology, computer science, telecommunications. Author of more than 20 scientific and educational works, 1 patent for a utility model.

ORCID ID: 0000-0001-5930-4592

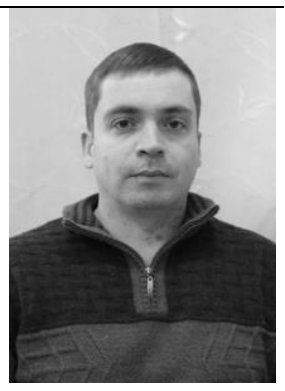

